\title{
Exploring the role of social capital influence variables on travel behaviour
}

\author{
Floridea Di Ciommo , Julio Comendador , María Eugenia López-Lambas , \\ Elisabetta Cherchi , Juan de Dios Ortúzar
}

\begin{abstract}
A B S T R A C T
This paper explores the potential role of individual trip characteristics and social capital network variables in the choice of transport mode. A sample of around 100 individuals living or working in one suburb of Madrid (i,e, Las Rosas district of Madrid) participated in a smartphone short panel survey, entering travel data lor an entire working week. A Mixed Logit model was estimated with this data to analyze shifts to metro as a consequence of the opening of two new stations in the area. Apart from classical explanatory variables, such as travel time and cost, gender, license and car ownership, the model incorporated two "social capital network" variables: participation in voluntary activities and receiving help for various tasks (i.e. child care, housekeeping. etc.). Both variables improved the capacity of the model to explain transport mode shifts. Further, our results confirm that the shift towards metro was higher in the case of people "helped" and lower lor those participating in some voluntary activities.
\end{abstract}

\section{Introduction}

To forecast the impacts of new transport policies and investments (new transport infrastructure, fare policies, congestion pricing, etc.), transport planners are particularly interested in analyzing transport demand and understanding the factors that explain travel choices and decisions. In particular, changes in mode choice may be due to a mixture of quantitative factors related to the characteristics of the alternative (e.g. travel cost and time) of the individual (e.g. income, age, social status and household size) and the context (i.e. trip purpose). In the transport modelling literature there has been an increasing awareness that the aforementioned attributes are not sufficient to characterize travellers and to forecast their travel behaviour. As a consequence, there is growing interest in investigating new variables and the literature has incorporated, for example, attitudes, habit, inertia and awareness in transport models (Ben-Akiva et al., 2002; Cantillo et al., 2007; Cherchi and Manca. 2011; Galdames et al., 2011; Domarchi et al., 2008; Prashker, 1979; Rieser-Schüssler and Axhausen, 2012; Yáñez et al., 2010b).

Recent studies have also recognized that users' social interactions - as well as their perceptions - may influence travel behaviour, especially when changes to the transport system are introduced (Ben-Akiva et al., 2012; Brock and Durlauf, 
2003; Carrasco and Miller, 2006). These studies have developed a general framework that extends choice models by including an explicit representation of the decision-making context. This context considers some specific elements of the social environment (i.e. family, friends, and market) that influence the process leading to a choice. Notwithstanding, key social influence variables are rarely included directly in travel behaviour models, possibly because of the difficulty in measuring the degree of integration of people with respect to their spatial proximity and social relationship (i.e. social capital network attributes).

In this paper we use data from a smartphone panel survey to examine mode choice after the opening of two new metro stations in Madrid. Based on current literature investigating the treatment of the interdependence between various decisionmakers and its influence on transport mode choice (Currie and Delbosc, 2010; Dugundji and Gulyas, 2003; Dugundji and Walker, 2005; Deutsch and Goulias, 2013; Moore et al., 2013), the questionnaire for our Madrid Panel included two specific questions about "social capital influence" for each individual; first, if they received some help for child-care or for housekeeping (Helped variable), and second if they voluntarily participated in some non-compulsory meetings or activities (Voluntary variable). We analyze the effect of these "social influences" in explaining the observed shift to metro over and above the classical quantitative attributes typically included in mode choice models (i.e., travel cost, income, trip purpose, gender and car ownership).

Our new variables relate to the individual social capital network including not only trip generating capacity (i.e. Voluntary) that could be similar to social network influence (i.e. go visiting relatives or friends), but exploring social capital network resources (i.e. Helped) that influence time availability/constraints and thus travel behaviour as well. Actually, previous work on transport and social exclusion has shown how the social capital network of a low-income group (i.e. Hispanics) influences its car availability and increases its mobility reducing its social exclusion risk (Blumenberg and Pierce 2012). We generalize this approach, by considering social capital network influence on low-income group's transport mode choices and adopt it for analyzing the travel behaviour of several groups of people.

Recent studies have also shown how built environment relations influence travel behaviour (TRB Committee on Physical Activity, Health, Transportation, and Land Use, 2005), where "built environment" includes all kind of spatial proximity variables (i.e. design of the site, population density, street pattern, land use mix, distribution of commerce, spatial structure and transport supply). However, social capital network influence variables are not included in the built environment, as this is typically measured through more spatial and infrastructure oriented variables. Therefore there is a real scientific interest in testing the inclusion of this type of variables in a discrete choice-modelling framework (Portney, 2005).

Theoretically speaking, social capital variables indicate the social embedding of people in their own contexts (Granovetter, 1985, 2005 Putnam et al., 1994; Di Ciommo, 2003). Actually, individuals could use social capital network integration for defining their own behavioural strategy (Granovetter, 1994). Putnam et al. (1994) found that there is a strong correlation between civic engagement (i.e. volunteering) and government and local urban services' quality across Italian regions; also, social capital network influence decreases with physical distance (Glaeser et al., 2002). In other words, the social capital network is related to spatial proximity. In this sense social capital variables are different from social network influence variables because they generate more local trips (i.e. voluntary activities are locally based) and they are different from spatial infrastructure variables because they include a soft set of social variables. Therefore, if the local community is social capital oriented, potential public policies to be implemented (including transport initiatives) may differ (Thiébault, 2003). The opening of new transport network infrastructure presents a challenge for social assessment, which should answer two main questions:

- How much of a modal shift will actually take place?

- What is the profile of users of the new transport infrastructure?

Discrete choice models are commonly used in transport planning applications. As discrete choice theory is fundamentally grounded on individual choices, the treatment of the inter-dependence of choices among various decision-makers' and their integration into social networks remains an outstanding challenge (Dugundji and Walker, 2005). Interestingly, due to the increasing awareness of the influence of social variables in travel behaviour, we now have evidence from a wide range of studies that individual outcomes are linked to social interaction factors, especially within social groups defined by geographic proximity (Brooks-Gunn et al., 1993; Glaeser et al., 1992; Bauer and Zimmermann, 1999). In particular, Ostrom (1998) modified the rational utility theory to include social interaction variables, such as reciprocity, trust and reputation, and obtained improved results. Brock and Durlauf (2001a, 2001b) and Skrondal and Rabe-Hesketh (2003), have expanded the effort to employ social interaction variables in a structural estimation with binary choice models. Durlauf (2002) looks for the empirics of social capital and explain how a survey could be oriented to detect social capital structure and provide deeper controls for individual heterogeneity.

Finally, the inclusion of Voluntary and Helped as social capital network variables seems to improve the set of currently used variables for estimating mode choices by combining the class of social network variables in generating social trips with the class of spatial proximity variables.

Following the discrete choice modelling trend of treating inter-dependence of choices and their integration into social networks, we incorporate our two social capital network variables directly into a Mixed Logit (ML) model (Train, 2009), as shown in Fig. 1. The choice of these two variables is related with two different dimensions of social capital: a passive one (receiving help) and an active one (to carry out voluntary activities). Both variables influence travel behaviour in a 


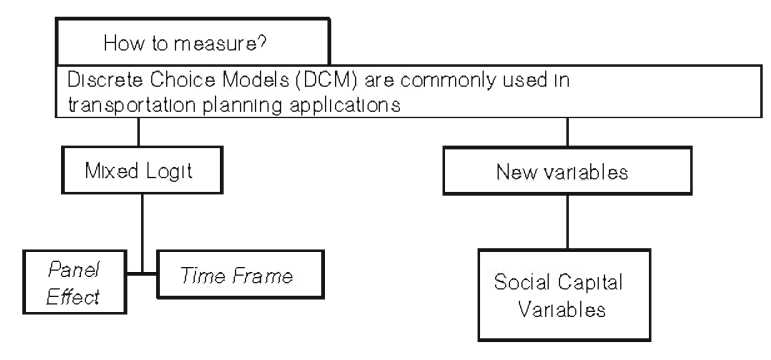

Fig. 1. The role of social capital variables in discrete choice models.

different way: the first one may liberate some additional time for travel, while the second one may generate new social trips and create an additional time constrained subgroup (Farber and Páez, 2009).

Voluntary activity is carried out within an individual's social network and generates social trips generally defined as visiting someone. Sharmeen and Timmermans (2013), using a multimodal logit mode choice model, show that for social trips half of the respondents in a Dutch survey sample used slow private modes, while $39 \%$ used car and only $11 \%$ used public transport. Using a ML model allows incorporating random heterogeneity in some key attributes, such as time and cost, and also to consider panel effects. Panel data are multi-day datasets in which repeated measurements on the same sample of units are gathered at certain points in time (Pas, 1988). Panel data usually offer significant advantages over cross-sectional data, as repeated observations from the same individual allow for more precise measurements of changes in individual mobility (Ortúzar and Willumsen, 2011).

The rest of the paper is organized as follows. A description of the panel smartphone data is reported in the next section, while the third section presents the base model estimated with this data. A synthesis of the estimation results including a discussion of the key variables for understanding changes to metro use is presented in section four. Finally, section five offers our conclusions about the role of "social capital" variables in explaining modal shift.

\section{The Madrid panel: a smartphone survey}

The recent enlargement of the public transport network of the Madrid Region took place within the framework of a longterm strategy. The Madrid Public Transport Authority - Consorcio Regional de Transporte de Madrid (CRTM) - considers the metro as the key mobility mode in the Madrid Metropolitan Area (MMA). The Madrid Metro Network Enlargement Plan 2007-2011, was completed with the inauguration of two new stations of Line 2, in March 2011.

The survey was designed to explore the factors influencing modal choice after the opening of the new metro line and consisted of two-stages:

(1) A simple revealed preference (RP) mode choice survey that was used as exploratory survey.

(2) A more thorough RP travel diary panel survey using smarthphones, where 100 users described their travel choices during one week.

For the exploratory survey, a sample of 1174 individuals was selected among those people already using the new stations. The survey included useful information such as trip characteristics (i.e. itinerary and travel purpose, as well as the main reason for the modal shift) both current and before the metro extension, relevant information about times and costs of trips (i.e. including type of public transport ticket used) and users' socio-economic attributes (gender and car ownership) to explain the characteristics of the sample (Cherchi and Ortúzar, 2002; Comendador et al., 2012). An important result of the exploratory survey was that people used the new metro stations mainly for work trips with log-odds of choosing metro over car equal to 1.24 (significant at the $95 \%$ level, Comendador et al., 2012). We used this data to build the panel survey conducted after opening the new metro stations.

Six months after the first RP exploratory survey and 8 months after the opening of the new metro stations, the panel smartphone survey was carried out in two stages; data was collected from residents and workers in areas near the new metro stations over the course of a working week (5 days), between October and December 2011.

The first stage was a face-to-face interview aimed at registering personal data about the respondents (it covered a wide variety of socio-economic variables). This interview was also used to explain the content and objectives of the survey and to ask two main questions about the social capital influences of residents and workers in the catchment area. In particular we asked:

- If they received some help for child-care or housekeeping (Helped dummy variable).

- If they participated in non-compulsory meetings or activities (Voluntary dummy variable). 
In this interview, we also asked if the respondent had changed mode after the new metro stations were opened, which allowed measuring the modal shift due to new infrastructure. At the end of this first phase respondents were also asked a couple of attitudinal and perception questions covering comfort, security and accessibility topics.

In the second stage, we provided respondents with a smartphone and asked them to register their trips during 5 days. Weekends were not included because we focused on work trips. In total, one hundred smartphones were distributed and the response rates were high ( $98 \%$ of the initial sample agreed to participate after contacted). Once people were convinced to participate in the survey, they made a significant effort to properly complete it using the equipment. We monitored the trips recorded in real time and eventually contacted respondents at the end of each day to correct or clarify the data. A chart was also given to manually register those trips that were not recorded in the smartphone. The complete registration of daily trips took on average $20 \mathrm{~s}$ for a trip by car or on foot, and one min for a public transport (PT) journey. At the end of the trip, the data were automatically sent to a server accessible by the survey monitor. The face-to-face questionnaire and the Smartphone trip diary followed the design of the palm-based Santiago Panel survey used for studying the TranSantiago system in Chile (Yáñez et al., 2010a).

Before conducting the panel survey, three focus groups were organized with residents of the stations' catchment areas; these allowed improving the questionnaire design, understand the perception of the new metro stations and define the profile of residents and workers to be recruited (Aizer and Currie, 2002). The focus groups were also used to design incentives to attract individuals to participate in the survey. The selected incentive was fifty gift cards of $20 €$ that were raffled among participants.

Table 1 shows the socio-economic characteristics of the Madrid Panel. As mentioned before the survey was based on a sample of individual workers and inhabitants of the catchment area. We note that it is fairly representative of the travelling population in the Madrid Metropolitan Area (MMA) suburbs, where 46.5\% of inhabitants and workers use car, 23\% take PT, 28.7\% walk, and 2.8\% take taxi or other services (Monzón et al., 2014).

There is an underrepresentation of men, because workers were mainly selected at the health care sector; ${ }^{1}$ participants were recruited during two previous informative meetings (on survey organization and its objectives) at the local Health Centre. There is also an over-representation of people between 24 and 45 years of age, the average revenue is quite high (65\% of the sample earns more than $€ 2000 /$ month, while the average income of the MMA is $€ 1650 /$ month) and households have four members on average. On the other hand, there is a significant share of people with a driving license and having daily car availability, and a low percentage of participants with a PT monthly travel pass. The distribution of the number of trips shows an expected peak around 10 to 14 trips per week but mode shares are $62.2 \%$ for car, $18.4 \%$ for walking, almost the same for PT ( $18.5 \%$ ) and 0.9 are multimodal trips.

When new infrastructure is introduced, transport planners are especially interested in defining its pro-modal-shift factors. But it is hard to know the real causes of a modal shift. Some studies about voluntary travel behaviour change have shown how much travel cost, together with cultural and social values, may influence or even determine traveller's mode choice (Ampt, 2003). For example, measures for promoting public transport are more effective for new residents and frequent PT users (Fujii and Taniguchi, 2006). Moreover, attitudes are not necessarily associated with observed behaviour; for example, a person who has a positive attitude to reduce car use cannot change to another mode if s/he lacks information about available alternatives (Eagly and Kulesa, 1997).

Following Bowman and Ben-Akiva (2000), who found that people travelling for work-related reasons had a higher probability of responding to mode changes, we focused on commuting trips to study modal shift. Table 1 shows that with the new metro extensions, $11.4 \%$ of trips to work change mode while only $3.4 \%$ of trips for other purposes shift to PT. Among the former $11.4 \%, 4.7 \%$ are Helped and Voluntary, while $2.5 \%$ are just Voluntary people. Among the latter "other purposes trips", social trips were mainly done by car. Sharmeen and Timmermans (2013) have shown that private modes (i.e. car, bike and walk) seem to be strictly preferred by Dutch survey respondents for social trips.

\section{The base model}

The modelling stage started with the estimation of a basic Multinomial Logit (MNL) model where the representative utility $V_{i q}$ of each alternative $i$ was considered a function of the observable level-of-services (LOS) characteristics $\left(X_{k i q}\right)$ of the alternative, choice situation (trip purpose, for example) and decision-maker $q$ (income, age, usual place of residence, gender, social capital variables); the set of parameters $(\beta)$ to be estimated included a full set of alternative specific constants (ASC). As usual, individual utility $U_{i q}$ was assumed to incorporate an additive error term $\varepsilon_{i q}$ following an identical and independent Type I Extreme value distribution (Ortúzar and Willumsen, 2011, chapter 7):

$$
U_{i q}=V_{i q}+\varepsilon_{i q}
$$

In this case, the choice probability for each alternative $i$ is defined as:

$$
P_{i q}=\operatorname{Prob}\left(\varepsilon_{j q} \leq \varepsilon_{i q}+V_{i q}-V_{j q}, \quad \forall j \neq i\right)=\frac{\exp \left(\lambda V_{i q}\right)}{\sum_{j} \exp \left(\lambda V_{j q}\right)}
$$

\footnotetext{
${ }^{1}$ In the Regional Health Department $67.8 \%$ of the working population is female.
} 
Table 1

Socio-economic attributes/characteristics of respondents.

\begin{tabular}{|c|c|c|c|c|}
\hline Attribute/characteristic & $\begin{array}{l}\text { Study } \\
\text { participants }\end{array}$ & & & $(\%)$ \\
\hline Gender & $\begin{array}{l}\text { Male } \\
\text { Female }\end{array}$ & & & $\begin{array}{l}26.0 \\
74.0\end{array}$ \\
\hline Age & $\begin{array}{l}\text { Under } 20 \\
20-25 \\
25-34 \\
35-44 \\
45 \text { and older }\end{array}$ & & & $\begin{array}{r}8.3 \\
4.2 \\
25.0 \\
62.5 \\
0.0\end{array}$ \\
\hline Household size & $\begin{array}{l}1 \\
2 \\
3 \\
4 \\
5 \text { or more }\end{array}$ & & & $\begin{array}{r}7.4 \\
26.9 \\
26.9 \\
31.3 \\
7.5\end{array}$ \\
\hline Montly income & $\begin{array}{l}\text { Less than } 1000 € \\
1000-2000 € \\
2000-3000 € \\
3000-4000 € \\
\text { Greater than } \\
4000 €\end{array}$ & & & $\begin{array}{l}13.9 \\
24.6 \\
26.2 \\
24.6 \\
10.7\end{array}$ \\
\hline Possession of driving license & Yes & & & 90.9 \\
\hline One or more cars per household & Yes & & & 83.5 \\
\hline Possession of monthly travel pass & Yes & & & 17.6 \\
\hline Number of trips per person per week & $\begin{array}{l}\text { Less than } 10 \\
10-14 \\
15-19 \\
20-24 \\
\text { Greater than } 30\end{array}$ & & & $\begin{array}{r}2.6 \\
59.7 \\
26.0 \\
6.5 \\
5.2\end{array}$ \\
\hline Trip purpose & $\begin{array}{l}\text { Work } \\
\text { Others }\end{array}$ & & & $\begin{array}{l}65.1 \\
34.9\end{array}$ \\
\hline Choice & $\begin{array}{l}\text { Public transport } \\
\text { Walk } \\
\text { Car } \\
\text { Multimodal }\end{array}$ & $\begin{array}{l}\text { Metro } \\
\text { Bus } \\
\text { Subur. } \\
\text { rail } \\
\text { Driver } \\
\text { Passenger }\end{array}$ & $\begin{array}{r}11.5 \\
6.5 \\
0.5 \\
\\
55.8 \\
7.3\end{array}$ & $\begin{array}{r}18.5 \\
18.4 \\
62.2 \\
0.9\end{array}$ \\
\hline Was travel mode changed for trips to work? & $\begin{array}{l}\text { Yes } \\
\text { No }\end{array}$ & & & $\begin{array}{l}11.4 \\
88.6\end{array}$ \\
\hline Was travel mode changed in trips for other purposes? & $\begin{array}{l}\text { Yes } \\
\text { No }\end{array}$ & & & $\begin{array}{r}3.4 \\
96.6\end{array}$ \\
\hline $\begin{array}{l}\text { Helped: "if you need help for certain tasks (child care, household chores, etc), do you have people who can } \\
\text { help you out?" }\end{array}$ & $\begin{array}{l}\text { Yes } \\
\text { No }\end{array}$ & & & $\begin{array}{l}59.7 \\
40.3\end{array}$ \\
\hline $\begin{array}{l}\text { Voluntary: "do you participate in meetings at district, neighborhood or work levels, even though attendance } \\
\text { is not mandatory?" }\end{array}$ & $\begin{array}{l}\text { Yes } \\
\text { No }\end{array}$ & & & $\begin{array}{l}42.9 \\
57.1\end{array}$ \\
\hline
\end{tabular}

where the scale parameter $\lambda$ is not identifiable (so we end up estimating coefficients multiplied by it) and $V_{i q}$ is typically a linear function in the coefficients $\beta$, but not necessarily in the attributes. In fact, our formulation includes several interactions among the LOS attributes and decision makers' characteristics that allow accounting for systematic heterogeneity in individual preferences (Ortúzar and Willumsen, 2011, page 279).

More general models allow relaxing the three classical restrictions of the MNL model (i.e., absence of random taste variations, unrestricted substitution patterns and correlation of unobserved factors over time, Ortúzar and Willumsen, 2011). In particular, the Mixed Logit (ML) model is completely general in the above senses and simulation of its choice probability is nowadays computationally simple (Train, 2009).

The ML model is, in particular, suitable to account for repeated choices by decision-makers, such as those made by the 100 people who participated in our panel survey over the course of a week. Our model specification considered the utility coefficients as varying between individuals but remaining constant through all choice situations for each person (Train, 2009). The ML probability that accounts for this panel effect takes the following form: 


$$
P_{\text {iq }}=\int \Pi_{t} P_{\text {iqt }}\left(\beta_{q}\right) f(\beta \mid \theta) d \beta
$$

where $P_{i q t}$ is the conditional choice probability (it has the same expression as in (2) but it is defined for each repeated choice t); the parameters $\beta_{q}$ (including the ASC) may vary according to a so called "mixing distribution" $f(\beta / \theta)$ over the population $(\theta$ are known as population parameters). Therefore, $P_{i q}$ is the unconditional probability that individual $q$ will choose the sequence of alternatives $i$ along time given a vector of individual-specific coefficients $\beta_{\mathrm{a}}$. The probability in (3) is a multidimensional integral that can be efficiently estimated through simulated maximum likelihood methods (Ortúzar and Willumsen, 2011, Chapter 8).

Our models considered three transport modes: public transport (PT), walking and car (which was taken as reference alternative). A set of LOS attributes, socioeconomic variables and other attributes were specified to explain choices. First, two LOS variables: total travel time from origin to destination (Total Travel Time) and cost specified as the ratio between the cost of travel and the available income of the traveller (Personal Travel Cost). The available income was calculated using the average transport consumption expenditure of Spanish households (i.e. 11.6\%, see EUROSTAT, 2012) as follows:

$$
\text { Personal Travel Cost }{ }_{i j q}=\text { travel cost } \cdot \frac{\text { monthly income }}{\text { average monthly trips }} \cdot \frac{0.116}{\text { household size }}
$$

We used total travel time (instead of in-vehicle time and access time) because of the high ratio between public transport and $\operatorname{car}$ (i.e.1.62 in average) times in the case of the Madrid suburbs. Therefore, the travel time competitiveness of the car is a fact even when out-of-vehicle times are not distinguished (Di Ciommo and Lucas, 2014).

On the other hand, LOS attributes for the non-chosen modes were estimated using the following data:

- Itinerary bus times and car time estimations from Google Maps (@2012 Google).

- Schedule times for buses and suburban rail published by the PT authority (EMT Navega por Madrid (C2010).

- Metro times from the real time information platform, Viaja en Metro (@2012) and

- Transport costs were estimated as $€ 0.90$ per trip by PT and $€$ 0.10/pax-km for car travel (Di Ciommo et al., 2013).

Three individual-specific variables were included as dummies that did not vary across alternatives: Gender, which takes the value of one for females; car ownership $(\mathrm{CO})$ which takes the value of one for households with one or more cars, and Purpose which takes the value of one if the trip was to work. Finally, our model included the two dummies (Voluntary and Helped) related with the social integration level of the decision-maker; these are two observable characteristics, in the sense that they explain a specific situation for each decision-maker. The first is a time consuming variable and the second a time saving variable; thus, both may influence travel behaviour, but probably in a different way.

\section{Model estimation results}

Individuals were considered to have a choice among the three modes of travel. Our study attempted to find out whether better models could be obtained when using social capital variables such as Voluntary and Helped. Table 2 reports the results of two ML models with different specifications, with and without the social interaction effects, to test the effects of their inclusion. The ML models were estimated using an own code (available on request from the authors) written within the $\mathrm{R}$ statistics package (Croissant, 2011).

As can be seen, all coefficients are significantly different from zero and have the expected sign. A log-likelihood ratio test on ML1 and ML2 confirms that for this particular case study, the latter has indeed higher explanatory power (these models were also clearly superior to their MNL counterparts, not shown in the table). Furthermore, with the inclusion of Voluntary and Helped almost all parameters increase their statistical significance except for Time and Gender. The marginal utility of total travel time seems to be influenced by both social interaction terms; this is expected, as a person doing more activities has less time and should reveal a higher value of time. On the other hand, people receiving help (e.g. in childcare) probably needs it and would not have enough time, otherwise, to deal with all their activities (interestingly, although they have relatively higher incomes they tend to choose PT and walk more often, spending more time); this helps explaining why their values of time are even higher than those who do voluntary activities, and therefore, they generally decide to not participate in voluntary activities (Putnam, 2000). The socioeconomic attributes also improve the statistical quality of model ML2, especially car ownership (CO) and the Work variable related with the Walk mode. In summary, these results confirm that observed behaviour is not only ruled by the typical LOS attributes, but also by a strong social influence component.

The results of model ML2 imply that the introduction of Voluntary reduces the probability of choosing Walk and PT, and has a non-linear influence on the utility function. This result could be explained by the effect of activities on mode choice: if somebody participates more in voluntary activities, s/he consumes more time than otherwise and may take more account of LOS variables (and in peripheral boroughs, such as the case study examined in this paper, this favors the car mode). In turn, Helped increases the probability of choosing Walk and PT (as when having some help for house and childcare, a person saves some time that can be used for travelling by foot or by public transport).

In both models the Work dummy, related to the PT mode, seems less important for the same reasons as above: the direct relationship between different activities (and Voluntary or Helped are two of them). 


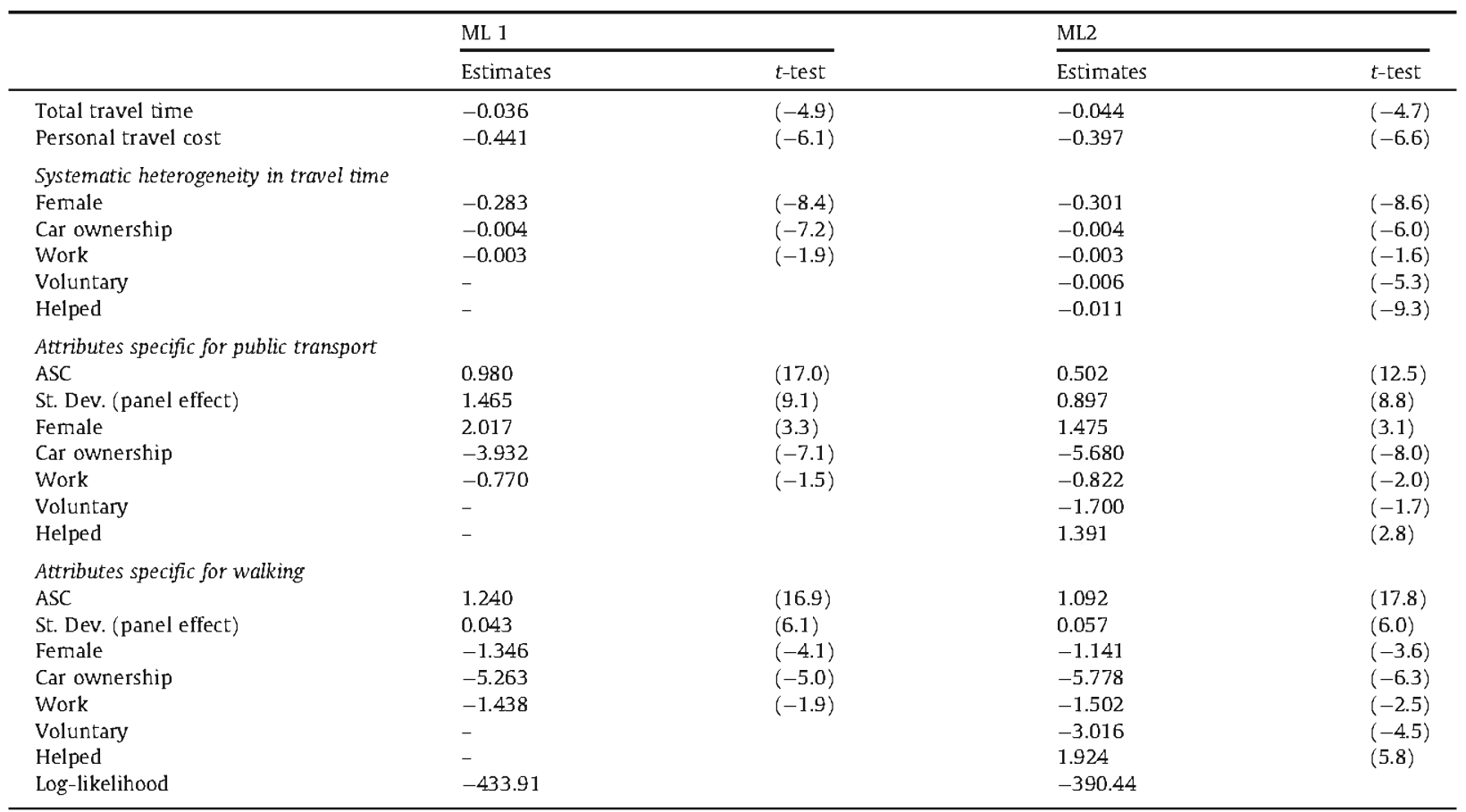

A breakdown in the analysis of Helped and Voluntary user types (Table 3) seems to confirm that the former freely choose PT as they have, on average, more cars and higher income; Voluntary users, on the other hand, have less access to cars and a relatively lower income, but freely decide not to use the new metro lines. However, the estimation of systematic heterogeneity in travel time for both social capital variables highlights the same negative sign for both types of users (i.e. they perceive negatively the time restriction). So, in this case the integration of social capital variables adds something to the neoclassical explanation of the effect of income on the value of time, which is an interesting result: car choice is not completely associated with a higher level of income. In fact, Voluntary users carry out more activities liberating some time by using the car intensively; their social embedding profile makes them more socially active people. Helped users, who are characterized by a different social embedding, are able to obtain help because of their higher income but decide to use their cars less as they have more time since they benefit from the time of others.

Table 3

Helped and voluntary user types.

\begin{tabular}{|c|c|c|c|}
\hline Socio-economic characteristics & Helped = 'yes' & Voluntary = ‘yes’ & Helped \& Voluntary = 'yes' \\
\hline Female & 66.7 & 71.9 & 68.8 \\
\hline Age & 43.2 & 43.0 & 43.0 \\
\hline Household size & 3.2 & 2.8 & 2.8 \\
\hline Monthly income (euros) & 2766.7 & 2468.7 & 2678.3 \\
\hline Driving license & 92.3 & 90.1 & 92.1 \\
\hline One or more cars & 84.4 & 78.1 & 80.5 \\
\hline$\%$ Monthly travel pass & 15.5 & 21.2 & 17.5 \\
\hline \multicolumn{4}{|l|}{ Weekly travel characteristics } \\
\hline Tours & 6.2 & 6.0 & 6.2 \\
\hline Time per trip & 34.0 & 27.6 & 29.9 \\
\hline Trips by car & 9.8 & 11.3 & 10.1 \\
\hline Trips by PT & 4.7 & 4.5 & 4.5 \\
\hline Walking trips & 5.9 & 5.6 & 6.0 \\
\hline Trips to work & 14.1 & 15.2 & 14.6 \\
\hline Non-working trips & 6.3 & 6.2 & 6.0 \\
\hline Car time (min) & 207.3 & 286.3 & 265.5 \\
\hline PT time (min) & 264.3 & 177.3 & 190.8 \\
\hline Walk time (min) & 222.4 & 126.7 & 140.7 \\
\hline Car distance $(\mathrm{km})$ & 8.2 & 9.0 & 8.7 \\
\hline PT distance $(\mathrm{km})$ & 3.8 & 2.7 & 3.0 \\
\hline Walking distance $(\mathrm{km})$ & 2.4 & 2.3 & 2.5 \\
\hline
\end{tabular}


In fact, time per trip for "helped" people is on average $34 \mathrm{~min}$, while time per trip for "voluntary" people is $27.6 \mathrm{~min}$. Di Ciommo and Lucas (2014) show that time ratios between public transport and car are quite high (i.e.1.62 in average) in the suburbs of Madrid. People involved in voluntary activities need to liberate time for their social trips. Therefore, as shown by Sharmeen and Timmermans (2013), these trips are more likely done by private modes (i.e. car, bike and walk) than by public transport. In general, for social trips people choose private modes that present additional degrees of "perceived" freedom with respect to PT (Jakobsson et al., 2000). People characterized by both variables Helped and Voluntary seem to combine mode choice criteria: they still prefer the car but less than just Voluntary people, and increase their PT use. Finally they definitely increase their walking distance even more than just Helped people. This result seems to point out to the conclusion that some social trips are done more easily by walking than using car (see Table 3).

\section{Conclusions and discussion}

Recent studies have recognized that users' social influences may affect travel behaviour, especially when new infrastructure is introduced (Ben-Akiva et al., 2002; Tudela et al., 2011; Durlauf, 2002), but to the best of our knowledge none has tested the effect of social capital variables directly into the mode choice models.

In this paper we were able to directly test the effect of two such variables (Voluntary and Helped) in mode choice after the opening of new metro stations in Madrid. We found that the two variables were highly significant and had an impact not only on the choice of mode but also on the marginal preference for travel time. Apparently, a linear influence exists between travel time and these variables. The main result of considering "helped" and "voluntary" user types is that social capital variables - as those tested here - could have a positive or negative impact on the use of public transport. We believe that this is a potentially important result for forecasting future public transport demand and to better understand what could be a favorable environment for increasing public transport use.

Our results show that "voluntary" people have a smaller probability of choosing public transport - PT- (see Table 2). For social trips all private modes (i.e. car, bike and walk) were found to be relevant in a Dutch survey while in our Spanish survey car use had the highest preference in comparison to PT and walk. Notwithstanding, it is clear that both the Dutch and Spanish cases point out that, for social trips, people choose private modes that present additional degrees of "perceived" freedom (Jakobsson et al., 2000). Another interesting result that links social capital with "voluntary" activities is related with the value of time: people whose value of time is higher, present a higher opportunity cost to be involved in voluntary activities, and as such they involve themselves less in them. Our results show the coherence of this hypothesis: the "voluntary" user type is characterized by a lower monthly income and a lower value of time. However, the joint profile of "Voluntary and Helped", shows an intermediate behaviour with a decreasing ratio of time spent by car, an increasing ratio of PT use and an increased walking distance (see Table 3). It seems that when "voluntary" people are also "helped", their attitudes/preferences with respect to walking change (i.e. they are prepared to walk longer distances than only "helped" people). Our results suggest that new potential measurable social capital variables for explaining travel behaviour, for example related with social media usage affecting the number of social trips, could be considered as having potential social capital network influence (Kamargianni and Polydoropoulou, 2014).

We expected that our two variables would influence travel behaviour in different ways because of their time consuming (Voluntary) or time saving (HeIped) effects. But social capital variables can have an opposite influence on travel behaviour with respect to an "income variable" and depend on the social profile of the individual. Therefore it is important to characterize preferences, characteristics and the social environment of people living in a specific neighbourhood regarding the use of public transport, walking and car. Based on that, policy makers could enlarge their criteria for deciding on public transport infrastructure implementation and selection of incentives for increasing the use of a specific transport mode.

The preliminary survey oriented towards detecting travel mode changes among residents and workers of areas near new metro stations confirmed that around $14.5 \%$ of travellers shifted to metro use. A lagged variable that would consider the mode choice made before an intervention could indeed be used to measure the effect of inertia, or propensity to change mode, and to link it with the social activities. This will be part of a further paper.

The survey also revealed that the majority of journeys were characterized as having a work purpose. However, this result is surely associated with the fact that the smartphone panel survey was developed during the five working week days, when social trips are probably reduced. We expect that the use of social capital network variables would influence the modelling of weekend days' trips, increasing their significance because of the increasing number of social trips during weekends.

A bias in our sample could be related with gender composition, making it not representative of the entire area population. However, both genders were included in the survey and this allowed showing that the inclusion of Helped and Voluntary social capital variables revealed that women and men have similar travel behaviour if there is increasing help in family duties and if people increase their activity levels with voluntary involvement.

Thus, the consideration of social capital influence variables allowed us to understand the reasons behind these modal shifts better. In particular, the Voluntary and Helped variables seem important in determining a specific travel behaviour, at least in the case of Madrid. 


\section{Acknowledgments}

The authors acknowledge the Spanish Research Ministry (MICINN) for its support in funding the project HABIT: Habit and Inertia in mode choice behaviour: a data panel for Madrid. We are also grateful for the cooperation of the Grupo de Aplicación de Telecomunicaciones Visuales (G@TV-UPM), Geographic Department (UCM) for designing the software application. The authors would also like to thank the statistical help offered by Conrado Gallardo from the Universidad Politécnica de Madrid. Finally, we are also grateful to the Millennium Institute in Complex Engineering Systems (ICM: P05-004F; FONDECYT: FB016), the Across Latitudes and Cultures-Bus Rapid Transit Centre of Excellence funded by the Volvo Research and Educational Foundations (VREF), the Alexander von Humboldt Foundation, and the Centre for Sustainable Urban Development, CEDEUS (Coni$\mathrm{cyt} /$ Fondap/15110020) for having contributed to this research. Finally, we are grateful to two anonymous reviewers for their constructive comments that contributed to improve an earlier version of this paper.

\section{References}

Aizer, A., Currie, J., 2002. Networks or Neighborhoods? Correlations in the Use of Publicly-Funded Maternity Care in California. NBER Working Paper 9209, National Bureau of Economic Research, Cambridge, Mass. (<www.nber.org/papers/w9209>).

Ampt, E., 2003. Voluntary household travel behaviour change: theory and practice. In: 10th International Conference on Travel Behaviour Research. Lucerne.

Bauer, T.K, Zimmermann, K.F., 1999. Assessment of Possible Migration Pressure and its Labour Market Impact Following EU Enlargement to Central and Eastern Europe. IZA Research Report No. 3, Institut zur Zukunft der Arbeit, Bonn. (<www.iza.org/en/webcontent/publications/reports/report pdfs/ report pdfs/iza report 03.pdf>).

Ben-Akiva, M., McFadden, D., Train, K., Walker, J., Bhat, C., Bierlaire, M., Bolduc, D., Boersch-Supan, A., Brownstone, D., Bunch, D.S., Daly, A., De Palma, A., Gopinath, D., Karlstrom, A., Munizaga, M.A., 2002. Hybrid choice models: progress and challenges. Marketing Lett. 13, $163-175$.

Ben-Akiva, M., De Palma, A., McFadden, D., Abou-Zeid, M., Chiappori, P.A, Lapparent, M., Durlauf, S., Fosgerau, M., Fukuda, D., Hess, S., Manski, C., Pakes, A., Picard, N., Walker, J., 2012. Process and context in choice models. Marketing Lett. 23, 439-456.

Blumenberg, E., Pierce, G., 2012. Automobile ownership and travel by the poor. Transp. Res. Rec. 2320, 28-36.

Bowman, J.L., Ben-Akiva, M., 2000. Activity-based disaggregate travel demand model system with activity schedules. Transp. Res. 35 A, 1-28.

Brock, W., Durlauf, S., 2001a. Interactions-based models. In: Heckman, J.J., Leamer, E.E. (Eds.), Handbook of Econometrics, vol. 5. Elsevier, Amsterdam, pp. $3297-3380$.

Brock, W., Durlauf, S., 2001b. Discrete choice with social interactions. Rev. Econ. Stud. 68, 235-260.

Brock, W., Durlauf, S., 2003. Multinomial choice with social interactions. NBER Technical Working Paper t0288, National Bureau of Economic Research, Cambridge, Mass. (<http://www.nber.org/papers/t0288>).

Brooks-Gunn, J., Klebanov, P.K., Liaw, F.R., Spiker, D., 1993. Enhancing the development of low-birth-weight, premature infants: changes in cognition and behaviour over the first three years. Child Dev. 64, 736-753.

Cantillo, V., Ortúzar, J. de D., Williams, H.C.W.L., 2007. Modelling discrete choices in the presence of inertia and serial correlation. Transp. Sci. 41, $195-205$.

Carrasco, J.A., Miller, E.J., 2006. Exploring the propensity to perform social activities: a social network approach. Transportation 33 , $463-480$.

Cherchi, E., Manca, F., 2011. Accounting for inertia in modal choices: some new evidence using a RP/SP dataset. Transportation 38, $679-695$.

Cherchi, E., Ortúzar, J. de D., 2002. Mixed RP/SP models incorporating interaction effects: modelling new suburban train services in Cagliari. Transportation 29, 371-395.

Comendador, J., Di Ciommo, F., López-Lambas, M.E., 2012. Habito o cómo medir la subjetividad en la movilidad del transporte urbano. In: Proceedings X Congreso de Ingeniería de Transporte. Granada (in Spanish).

Croissant, Y., 2011. Estimation of muLtinomial Logit Models in R: The Mlogit Package. Université de la Réunion, Saint-Denis.

Currie, G., Delbosc, A., 2010. Modelling the social and psychological impacts of transport disadvantage. Transportation 37, $953-966$.

Deutsch, K., Goulias, K, 2013. Decision makers and socializers, social networks and the role of individuals as participants. Transportation $40,755-771$.

Di Ciommo, F., 2003. Intêrêt ou Fiabilitê?: La Participation des Acteurs Econoniques aux Projets de Régênêration Urbaine à Naples, Paris et Milan. Doctoral dissertation, Laboratoire Techniques Territoires et Sociêtês, Unitê mixte de recherche CNRS 8134 (in French).

Di Ciommo, F., Lucas, K., 2014. Evaluating the equity effects of road-pricing in the European urban context-The Madrid Metropolitan Area. Applied Geography 54, 74-82.

Di Ciommo, F., Monzón, A., Fernandez-Heredia, A., 2013. Improving the analysis of road pricing acceptability surveys by using hybrid models. Transp. Res. 49 A, 302-316.

Domarchi, C., Tudela, A., González, A., 2008. Effect of attitudes, habit and affective appraisal on mode choice: an application to university workers. Transportation 35, 585-600.

Dugundji, E.R., Gulyas, L., 2003. Empirical estimation and multi-agent based simulation of a discrete choice model with network interaction effects. In: Proceedings 8th International Conference on Computers in Urban Planning and Urban Management, Sendai.

Dugundji, E.R., Walker, J.L., 2005. Discrete choice with social and spatial network interdependencies: an empirical example using mixed generalized extreme value models with field and panel effects. Transp. Res. Rec. 1921, 70-78.

Durlauf, S.N., 2002. On the empirics of social capital. Econ. J. 112, 459-479.

Eagly, A.H., Kulesa, P., 1997. Attitudes, attitude structure, and resistance to change: implications for persuasion on environmental issues. In: Bazerman, M.H., Messick, D.M., Tenbrunsel, A.E., Wade-Benzoni, K.A. (Eds.), Environment, Ethics, and Behaviour: The Psychology of Environmental Valuation \& Degradation. The New Lexington Press, San Francisco, pp. 105-121.

EUROSTAT 2012. Eurostat database (C) European Union, 1995-2012. (<http://epp.eurostatec.europa.eu/portal/page/portal/statistics/search database>). (Accessed 13.09.12).

Farber, S., Páez, A, 2009. My car, my friends and me: a prelininary analysis of automobility and social activity participation. J. Transp. Geogr. 17 (3), $216-$ 225.

Fujii, S., Taniguchi, A., 2006. Determinants of the effectiveness of travel feedback programs - a review of communicative mobility management measures for changing travel behaviour in Japan. Transp. Policy 13, 339-348.

Galdames, C., Tudela, A., Carrasco, J.A., 2011. Exploring the role of psychological factors on mode choice models using a latent variables approach. In: 90th Annual Meeting of the Transportation Research Board, Washington, D.C.

Glaeser, E., Kallal, H., Scheinkman, J.Y., Shleifer, A., 1992. Growth in cities. J. Polit. Econ. 100, 1126-1152.

Glaeser, E.L., Laibson, D., Sacerdote, B., 2002. An economic approach to social capital. Econ. J. 112, $437-458$.

Granovetter, M., 1985. Economic action and social structure: the problem of embeddedness. Am. J. Sociol. 91, 481-510.

Granovetter, M., 1994. Les institutions économiques comme constructions sociales: un cadre d'analyse. In: Orléan, A. (Ed.), Analyse Economique des Conventions. Presse Universitaire de France, Paris, pp. $79-94$ (in French).

Granovetter, M., 2005. The impact of social structure on economic outcomes. J. Econ. Perspect. 19, 33-50.

Jakobsson, C., Fujii, S., Gärling, T., 2000. Determinants of private car users' acceptance of road pricing. Transp. Policy 7, $153-158$. 
Kamargianni, M., Polydoropoulou, A., 2014. Social networking effect on net generation's trip making behaviour: findings from a latent class model. In: 93 rd Annual Meeting of the Transportation Research Board, Washington, D.C.

Monzón, A., Cascajo, R., Muñoz, B., Alonso, A., 2014. Informe del Observatorio de la Movilidad Metropolitana 2010. Ministerio de Agricultura, Alimentación y Medio Ambiente, Madrid.

Moore, J., Carrasco, J.A., Tudela, A., 2013. Exploring the links between personal networks, time use, and the spatial distribution of social contacts. Transportation 40,773-788.

Ortúzar, J. de D., Willumsen, L.G., 2011. Modelling Transport, fourth ed. John Wiley and Sons, Chichester.

Ostron, E., 1998. A behavioural approach to the rational choice theory of collective action. An. Polit. Sci. Rev. 92, 1-22.

Pas, E.I., 1988. Weekly travel-activity behaviour. Transportation 15, 89-109.

Portney, K., 2005. Civic engagement and sustainable cities in the United States. Publ. Administration Rev. 65, $579-591$.

Prashker, J.A., 1979. Mode choice models with perceived reliability measures. Transp. Eng. J. 105, $251-262$.

Putnam, R.D., 2000. Bowling Alone: The Collapse and Revival of American Community. Simon and Schuster, New York.

Putnam, R.D., Leonardi, R., Nanetti, R.Y., 1994. Making Democracy Work: Civic Traditions in Modern Italy. Princeton University Press, Princeton.

Rieser-Schüssler, N., Axhausen K.W., 2012. Investigating the influence of the environmentalism and variety seeking on mode choice. In: 91th Annual Meeting of the Transportation Research Board, Washington, D.C.

Sharmeen F., Timmermans, H.J.P., 2013. Modeling long term dynamics of mode choice for social trips. In: Proceedings Transport, Infrastructures, and Logistics (TRAIL) Congress, Delft.

Skrondal, A., Rabe-Hesketh, S., 2003. Multilevel logistic regression for polytomous data and rankings. Psychometrika 68, $267-287$.

Thiêbault, J.L., 2003. Les travaux de Robert D. Putnam sur la confiance, le capital social, l'engagement civique et la politique comparêe. Revue Internationale de Politique Comparêe 10, 341-355 (in French).

Train, K.E., 2009. Discrete Choice Methods with Simulation, second ed. Cambridge University Press, Cambridge.

Transportation Research Board \& Institute of Medicine. 2005. Does the built environment influence physical activity? Examining the evidence, TRB Special Report, 282 Transportation Research Board, Washington, D.C.

Tudela, A., Habib, K.M.N., Carrasco, J.A., Osman, A.O., 2011. Incorporating the explicit role of psychological factors on mode choice: a hybrid mode choice model using data from an innovative psychometric survey. In: 2nd International Choice Modelling Conference, Leeds.

Yáñez, M.F., Mansilla, P., Ortúzar, J. de D., 2010a. The Santiago Panel: measuring the effects of implementing Transantiago. Transportation $37,125-149$.

Yáñez, M., Raveau, S., Ortúzar, J. de D., 2010b. Inclusion of latent variables in mixed logit models: modelling and forecasting. Transp. Res. 44 A, $744-753$. 